\title{
Bone Remodeling, Particle Disease and Individual Susceptibility to Periprosthetic Osteolysis
}

\author{
J. GALLO ${ }^{1}$, M. RAŠKA ${ }^{2}$, F. MRÁZEK ${ }^{2}$, M. PETřEK ${ }^{2}$ \\ ${ }^{1}$ Department of Orthopedics, Palacký University Faculty of Medicine \& University Hospital, \\ Olomouc, ${ }^{2}$ Department of Immunology, Palacký University Faculty of Medicine, Olomouc, Czech \\ Republic
}

Received October 18, 2006

Accepted March 12, 2007

On-line April 25, 2007

\begin{abstract}
Summary
Bone remodeling is a tightly coupled process consisting of repetitive cycles of bone resorption and formation. Both processes are governed by mechanical signals, which operate in conjunction with local and systemic factors in a discrete anatomic structure designated a basic multicellular unit (BMU). The microenvironment around total joint arthroplasty is a dynamic and complex milieu influenced by the chemical and physical stimuli associated with servicing the prosthesis. A key factor limiting the longevity of the prosthesis is polyethylene wear, which induces particle disease, and this may lead to increased and prolonged activity of BMUs resulting in periprosthetic osteolysis. Several pathways regulating BMU function have been reported in the past, including RANKL/RANK/OPG/TRAF6, TNF-a/TNFR/TRAF1, and IL-6/CD126/JAK/STAT. Moreover, the expression and functional activity of all these molecules can be affected by variations in their genes. These may explain the differences in severity of bone defects or prosthetic failure between patients with similar wear rates and the same prosthesis. Simultaneously, this data strongly support the theory of individual susceptibility to prosthetic failure.
\end{abstract}

\section{Key words}

Periprosthetic osteolysis - Particle disease - Basic multicellular unit $\bullet$ Osteoclast $\bullet$ Osteoblast

\section{Corresponding author}

Jiri Gallo, Department of Orthopaedics, I.P. Pavlova 6, Olomouc 775 20, Czech Republic. Fax: +420 58844 3607. E-mail: jiri.gallo@volny.cz

\section{Introduction}

Total hip arthroplasty (Fig. 1) continues to be one of the safest and most effective surgical therapies. Nevertheless, the long-term outcome of this procedure is gradual deterioration over time in service resulting in increased rate of revisions due to aseptic loosening and osteolysis (OL). Both mechanical and biological factors trigger a cascade of events leading to the distortion of local bone homeostasis in favor of resorption. At least two types of periprosthetic OL may be distinguished: linear and aggressive. The former demarcates prosthesis with either a thin or a heavy fibrous membrane lying as a pad on the sclerotic bone surface. The latter differs from the former by lacking sclerotic adaptation of the bone surfaces. Poorly organized fibrous tissues may fill the bone lesions; thus, OL may be associated with loosening of the prosthesis.

Particle disease theory was coined to explain the pathophysiology of OL and prosthetic loosening (Harris 1994). This is based on the evidence that macrophages and other cells of mesenchymal origin release a multitude of cytokines, chemokines, metalloproteinases, and other agents after stimulation by prosthetic wear particles (Purdue et al. 2006). Ultimately, these substances mediate increased local concentration of mature and functionally competent osteoclasts that execute bone resorption. Simultaneously, prosthetic particles and substances of particle disease suppress osteoblast activities. Concurrently, mechanical factors such as 

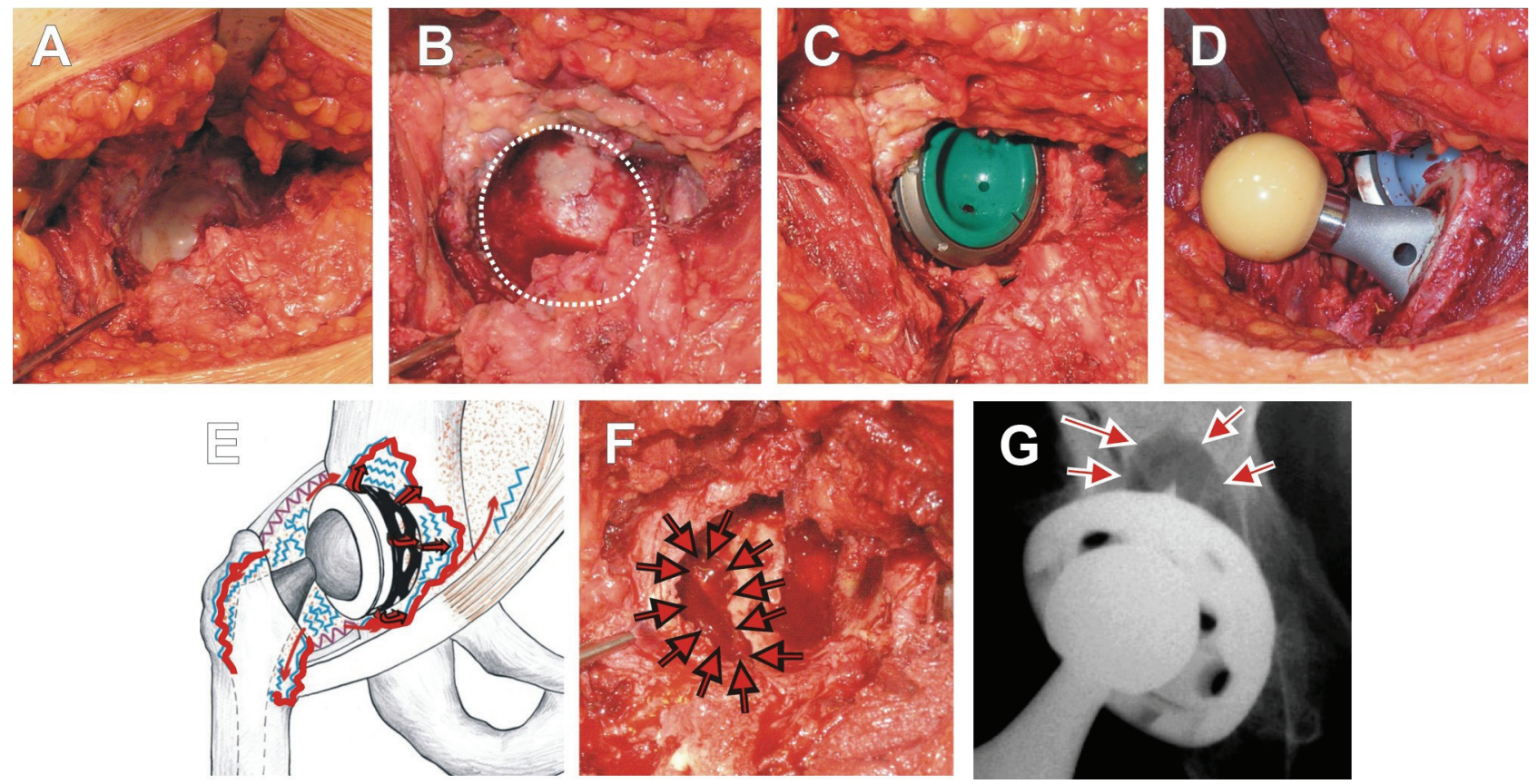

Fig. 1. Total hip replacement and periprosthetic OL. Acetabulum after removing of femoral hip moiety (A) is prepared - white dotted line (B) to fit with cementless cup which is positioned (C) before assembling total hip replacement (D). In case of OL the wear debris and proinflammatory and osteoclastogenic substances are spread out over the prosthesis (E) resulting in development of osteolytic granuloma that causes OL - as demarked by red arrows in perioperative picture (F) or in X-ray photograph (G).

excessive forces generated at the prosthesis-bone interface and joint fluid produced by surface macrophages of the synovium are involved in the etiology of OL (Sundfeldt et al. 2006). Both can lead to direct bone resorption independently of other factors.

The aim of this minireview is to present particle disease as a deviation in the balance of osteoblastosteoclast interactions within the BMU (basic multicellular unit). Furthermore, the concept of individual susceptibility to periprosthetic OL is introduced to explain the varying degrees of OL in patients with similar wear rates and prosthesis design. We believe this could lead to the development of more effective preventive and therapeutic strategies in the future.

\section{Particle disease: macrophage overstimula- tion by prosthetic particles}

Briefly, prosthetic particles are released by the artificial joint surfaces through the mechanisms of wear. In the case of polyethylene (PE) cup and metallic ball the rate of release has been estimated at 100000 - 500000 micron-sized particles for each step the patient takes (McKellop et al. 1995). After opsonization by plasma proteins or directly, prosthetic particles are phagocytosed by macrophages, which are then activated to release matrix metalloproteinases, chemokines, and cytokines (Purdue et al. 2006). The released factors increase vascular permeability, recruit other monocytes, activate innate and adaptive immunity, and support multinucleated osteoclast formation and activation - all of them leading ultimately to a shift in bone homeostasis towards resorption. In reality, macrophages are not the only cells endowed with the ability to phagocytose wear particles. Interface tissue fibroblasts (ITF), osteoblasts, and some other cell populations have the same ability. If particle size is over the phagocytosable limit, multinuclear foreign-body giant cells are formed (Ma et al. 2005). It remains to be elucidated whether the multinuclear cells represent a source of alternative osteoclast precursors induced by non-phagocytosable wear particles, or if they play another role in particle disease.

The monocyte/macrophage cell line is not only an initiator of osteoclast differentiation. It also serves as precursor for osteoclast lineage. The most important pathway involved in osteoclast maturation and activation is mediated by receptor activator of nuclear factor- $\kappa \mathrm{B}$ (RANK) and RANK ligand (RANKL) (Boyle et al. 2003). Activation of RANK by its ligand leads to the initiation of osteoclast-specific genes. Both TNF- $\alpha$ (tumor-necrosis factor) and IL-1 (interleukin) promote 
RANKL expression on marrow stromal cells, T-lymphocytes, ITF, and osteoblasts and this appears to be an inevitable precondition for osteoclast maturation (Fig. 2). In contrast, osteoprotegerin (OPG) blocks osteoclast formation by binding to RANKL (Boyce et al. 2006). The most potent secretors of OPG are dendritic cells, ITF, osteoblasts and their precursors (Koreny et al. 2006). A number of studies have recently shown that the local ratio between RANKL and OPG significantly influence the size of periprosthetic OL (Holding et al. 2006, Mandelin et al. 2003, Veigl et al. 2007). Using cDNA microarrays, induction of gene expression in macrophages and other involved cells has been found to be much more extensive and more complex than had been thought until recently (Garrigues et al. 2005, Guenther et al. 2005). Further progress may be expected in relation to pathway-focused DNA microarrays designed specifically for studying gene expression associated with particle disease.

Pure particle disease theory, however, cannot explain irregularities such as different rates of failure (OL) in patients with the same prosthesis and wear rate (Gallo et al. 2006; Wilkinson et al. 2005). Surprisingly, the number of particles released into the periprosthetic tissues can achieve levels in the order of $10^{12}$ even if the rate of prosthetic wear is $0.1 \mathrm{~mm}$ per year (Pokorný et al. 2006). Such a quantity of particles would undoubtedly trigger particle disease. Thus, not only particles per se but other factors must also be involved in the pathophysiology of OL. These may include hypersensitivity to prosthetic materials (Willert et al. 2005) or polymorphisms in the genes encoding for molecules involved in the pathways associated with OL (cytokines, enzymes, chemokines) (Ambruzová et al. 2006, Malik et al. 2006, Wilkinson et al. 2003). In addition, adherence of endotoxins to prosthetic particles markedly increases their biological activity. Hence, Nalepka et al. (2006) has proposed low-grade sepsis or systemic bacteriemia as another important factor in $\mathrm{OL}$ development.

\section{Bone remodeling: lessons learned from academic discussions}

Bone remodeling is the process by which the bone adapts its shape to external forces. It takes place at the bone surface, and key players are osteoblasts and osteoclasts (Sims and Baron 2002). The complete bone remodeling cycle consists of activation-resorption followed by activation-formation sequences both of them closely coupled and balanced at each BMU, thus guaranteeing the functional capacity of the bone under physiological conditions (Parfitt 2002). Formerly, it was thought that osteoblasts control the formation and activity of osteoclasts, and "make all decisions" in the BMU. Recently, it has been postulated that osteoclasts also contribute significantly to the local homeostasis by stimulating the osteoblast cell lineage (Martin and Sims 2005). Osteoblasts, osteoclasts, their precursors and other present cells are engaged in cell-cell interactions via a variety of mechanisms including secretion of long-range (hormones) and short-range signalling molecules (BMP-2, Wnt, M-CSF, RANKL, IL-6, IL-1 $\beta$, and IFN- $\gamma$ ), and direct cell-cell contact (communicating gap junctions, RANKL:RANK) (Stains and Civitelli 2005). In addition, each BMU is influenced by the immune system through both soluble and membrane-bound cytokines, and growth factors (Yeung 2005).

In contrast, uncoupling occurs when the balanced link between formation and resorption is disturbed (Martin and Sims 2005). In this regard, particle disease may be an example of a factor that profoundly changes parameters in favor of resorption. Within the context of particle disease, the final degree of bone loss depends on the number of uncoupled BMUs present at one time. Theoretically, this may be brought into effect by either increasing the lifespan of existing BMUs and/ or the origination of new BMUs (Parfitt 2002). Thus, the underlying mechanism for uncoupling of bone resorption from formation may lie in the number of functional osteoclasts and osteoblasts inside each BMU, which depends on perturbations in cytokine/chemokine milieu, vascular supply and concentration of osteoclast precursors in the blood.

Apoptosis is the key mechanism of cell number regulations with many positive and negative regulators including the above-mentioned soluble signals and cellto-cell interactions. PE-particle-induced cytokines such as IL-1, M-CSF, and notably TNF- $\alpha$ and RANKL support osteoclast survival mostly by stimulation of TRAFactivated pathways (NF-אB, ERK, PKB/Akt) (Blair et al. 2005, Xing and Boyce 2005). This stimulation may be so strong that can even protect osteoclasts from bisphosphonate-induced apoptosis (Zhang et al. 2005). Moreover, TNF- $\alpha$ induces apoptosis much easier in less mature osteoblasts than in mature ones (Xing and Boyce 2005). Simultaneously, prosthetic particles and agents of particle disease suppress the osteogenic activity of 

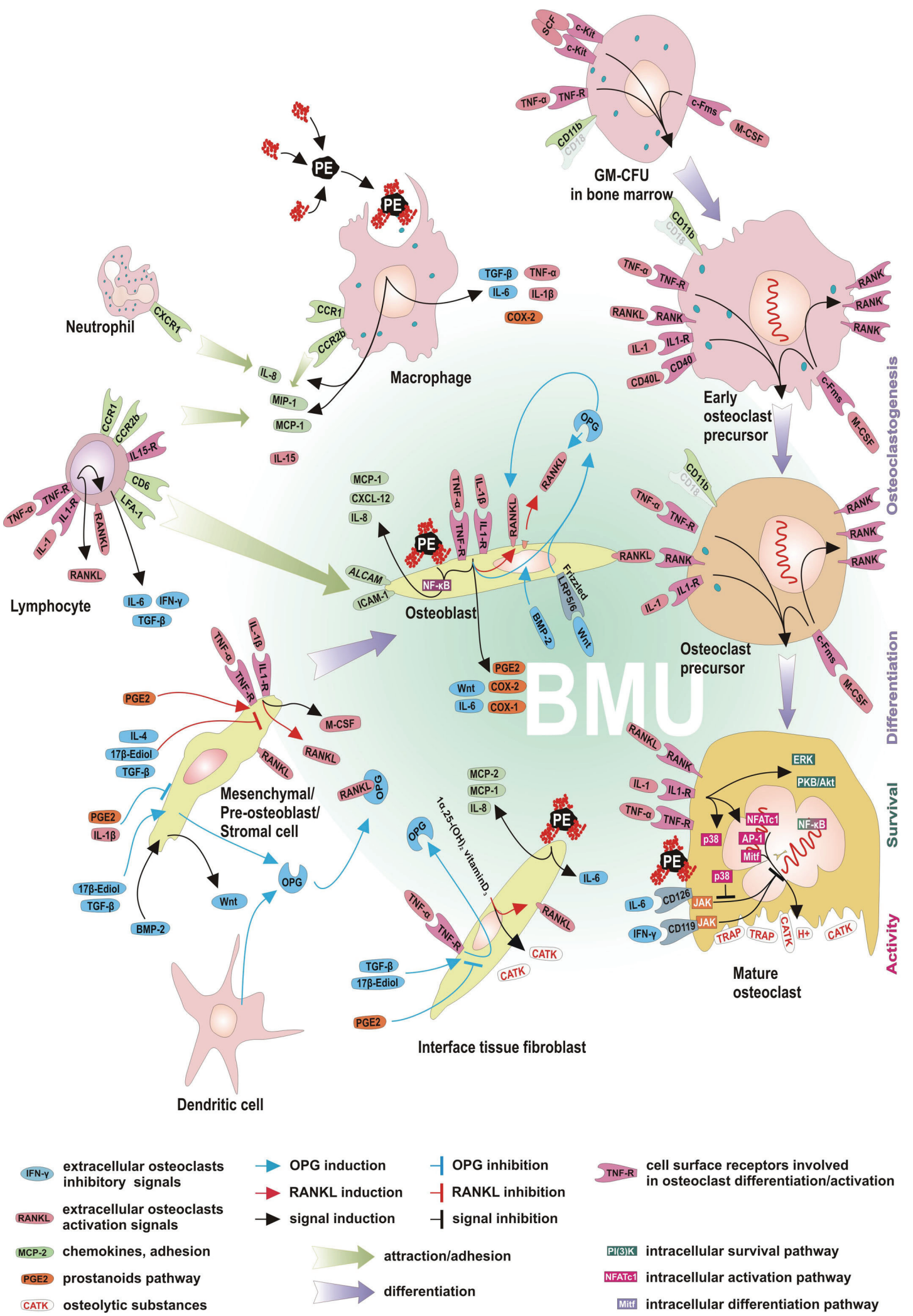

Fig. 2. Schematic representation of pathways participating in development of periprosthetic OL. Microenvironment of the bone multicellular unit (BMU) is regulated by signals arising either from BMU cells (osteoblasts, osteoclasts, stromal cells) or from attracted cells (macrophages, lymphocytes, neutrophils, ITF and dendritic cells). These signals can either stimulate (M-CSF, RANKL, TNF- $\alpha$, IL-1 $\beta$, wear particles, CD40L) or dampen (OPG, IL-6, IFN- $\gamma$, TGF- $\beta$, Wnt, BMP-2, IL-4) the osteoclasts formation and activity. Separately prostanoid pathway components (PGE2, COX-1, COX-2) involved in osteoclast stimulation and chemokines (MCP-1, MIP-1, IL-8, CXCL-12) attracting immune cells are depicted. 
residual osteoblasts. In addition, prosthetic particles provoke the expression of chemokines MCP-1, MCP-2, IL-8, which attract monocytes, T cells, and neutrophils. Intense local accumulation of such cell types not only creates conditions for continuation of inflammatory pathways but also increases the degree of tissue damage caused by necrosis.

\section{Osteoblasts}

Osteoblasts are bone-lining cells derived from mesenchymal stem cells of the bone marrow stroma or periost (Sims and Baron 2002). They never act individually but in groups when they synthesize a number of substances, including bone matrix constituents, and participate in several pathways through regulating immune and non-immune factors (IL-6, IL-8, MCP-1, CXCL-12, COX-1, COX-2, PGE2, M-CSF, FGF-2, RANKL, OPG, Wnt) (Krishnan et al. 2006). Among other signals, osteoblasts activity are strongly regulated by surrounding $\mathrm{pH}$ and growth factors released from resorpted bone matrix that stimulate osteoblasts to promote bone formation (coupling concept).

In vitro experiments have shown that wear debris alone or in conjunction with TNF- $\alpha$ or IL- $1 \beta$ stimulate mature osteoblasts toward the expression of chemokines MCP-1, IL-8, and CXCL-12 via a NF-אB pathway (Fritz et al. 2006). Osteoblasts can participate in the initiation of local inflammation by attracting monocytes, $\mathrm{T}$ cells, and neutrophils. Moreover, low concentration of particles, TNF- $\alpha$ and IL-1 $\beta$ may stimulate osteoblasts toward expression of the membrane-bound or soluble RANKL, and M-CSF thus participating in osteoclast recruitment, maturation, and activation (Boyce et al. 2005; Tanaka et al. 2005). On the other hand, the same cytokines can also induce expression of OPG, IL-6, and Wnt in osteoblasts (Krishnan et al. 2006) resulting in inhibition of cathepsin K (CATK) and tartarate-resistant acid phosphatase (TRAP) expression in mature osteoclasts via the JAK/STAT pathway (Rakshit et al. 2006). In fact, Wnt serves as an autocrine stimulator of OPG expression in osteoblasts. Furthermore, osteoblasts can actively bind immune cells ( $\mathrm{T}$ cells) by surface expression of adhesive molecules ICAM1 and ALCAM-1 (Stanley et al. 2006).

\section{Osteoclasts}

Osteoclasts are multinuclear giant bone resorbing cells that are usually located one or two per one resorption site (Sims and Baron 2002). Early osteoclast mononuclear precursors differentiate from hematopoietic progenitors of the monocyte/macrophage lineage (GM$\mathrm{CFU}$ ) under specific local milieu, which includes the presence of specific cells, and soluble factors (SCF, MCSF, TNF- $\alpha$ ). Once progenitor lineage cells differentiate to early osteoclast precursors they express RANK on their surface (Boyce et al. 2006). Binding of RANKL to RANK molecule stimulates further differentiation toward osteoclasts. RANKL exist in both surface-bound and soluble form. The former is expressed on the particlestimulated osteoblasts and ITF (Mandelin et al. 2005). The latter is secreted by several cell lineages ( $\mathrm{T}$ cells, osteoblasts, stromal cells) after stimulation by particleinduced TNF- $\alpha$, IL-1 $\beta$ and $\mathrm{PGE}_{2}$ (Boyce et al. 2005). At this stage, the osteoclast precursors may be activated to further differentiation by IL-1 $\beta$ (Blair et al. 2005). Simultaneously, macrophage and $\mathrm{T}$ cell recruitment is reinforced by chemokines MCP-1, MCP-2, MIP-1, and IL-8 released from BMU cells. These interactions result in a cascade of positive feedback further supporting osteoclast maturation and activation (Fig. 3), eventually leading to high concentrations of mature and active osteoclasts with prolonged survival in BMU.

This differentiation and activation process is down-regulated by soluble RANKL-decoy factor (OPG), IL-6, IFN- $\gamma$, IL-4, and other as yet not well-understood factors (Blair et al. 2005). OPG is secreted predominantly by regulatory-acting dendritic cells, ITF (see below), and osteoblasts as the negative feedback response to increased surrounding concentration of TNF- $\alpha$ and IL-1 $\beta$. OPG secretion is also stimulated by regulatory antiinflammatory cytokines TGF- $\beta$, IL- 4 , and factors such as hormone $17 \beta$-estradiol or differentiation factor $\mathrm{Wnt}$ (Krishnan et al. 2006). The high affinity of binding RANKL to OPG precludes a dispersed osteoclastogenic environment, supporting the hypothesis that for effective osteoclast formation, direct cell to cell contact between RANKL-positive cells (ITF, osteoblasts) and precursor cells expressing RANK is required in interface tissue (Stains and Civitelli 2005).

A gradual increase in expression of osteolytic substances (CATK, TRAP) during osteoclastogenesis is possible, owing to the large number of transcription factor binding sites in regulatory sequences of respective genes (Blair et al. 2005; Boyce et al. 2006). These binding sites are cumulatively occupied by transcription factors (PU.1, Mitf, NFATc1, AP-1, and NF- $\mathrm{BB}$ ) whose intracellular level increases during the monocyte to 


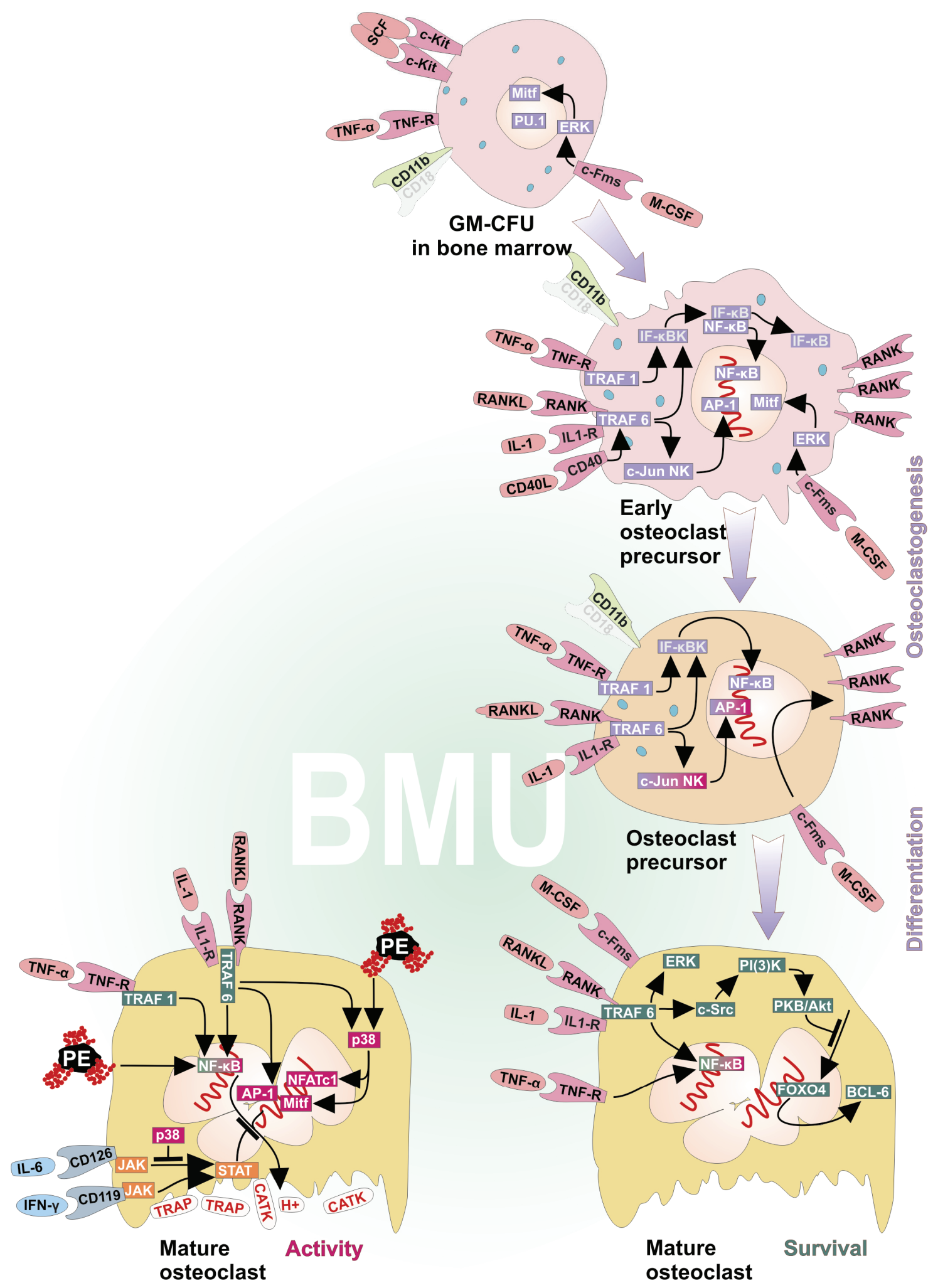

Fig. 3. Induction of the osteoclast differentiation, survival, and activity. Osteoclasts differentiate from GM-CFU progenitor in bone marrow. First osteoclast precursors begin to express RANK and migrate to ossificated bone (BMU) under specific signaling where the differentiation is completed. Mature osteoclasts require extracellular signals for survival and activity that is associated with osteolysis. 
osteoclast differentiation and activation. Down-regulation of CATK and TRAP transcription has been observed during osteoblast IL-6 secretion; interestingly, IL-6 may be expressed by macrophages and ITF as well. Another down-regulator is IFN- $\gamma$, which stimulates the JAK/STAT pathway after binding to osteoclast surface receptor CD119 as does IL-6. However, direct binding of wear particles on osteoclast surface, which causes the induction of various MAP kinase pathways, regulating JAK/STAT cytokine response, may dampen the interferon-suppressive effect. It has been shown that IL-6-induced JAK/STAT signaling is suppressed by the p38 MAP kinase pathway, which is activated by RANKL and IL-1 TRAF6-mediated activation (Rakshit et al. 2006). Thus, the wear debris is not only a stimulus for inflammatory and osteoclastogenic response. It also suppresses the naturally evolved homeostatic regulatory mechanisms directing the BMU (Fig. 3).

\section{Interface tissue fibroblasts (ITF)}

Fibroblasts are dominant cell type at the interface tissue membrane that play important role in the control of osteoclastogenesis after direct particle-induced or indirect stimulation (hormones or cytokines) resulting in secretion of chemokines including MCP-1, MCP-2, IL-8, matrix metalloproteinases, and cytokines such as TNF- $\alpha$ and RANKL (Koreny et al. 2006). Recently, in vitro experiments confirmed that the only factor that consistently increased RANKL production in ITF was not TNF- $\alpha$ or IL- $1 \beta$ but $1 \alpha, 25-(\mathrm{OH})_{2}$ vitamin $\mathrm{D}_{3}$. In contrast, OPG expression was effectively regulated by hormones and cytokines including TNF- $\alpha$ (Mandelin et al. 2005). ITF participate also through cell-to-cell interactions with osteoclast precursors. Moreover, they can contribute to lower $\mathrm{pH}$ and produce CATK (Mandelin et al. 2005). On the other hand, ITF can down-regulate osteoclast activation by IL-6 production (Konttinen et al. 2002). Thus, ITF actively contribute to both up- and/or down-regulation of the osteolytic microenvironment between prosthesis and bone.

\section{Lymphocytes}

Perivascular infiltrates of lymphocytes have been observed in tissues from patients with aseptic loosening or osteolysis (Willert et al. 2005). Wear particles-activate macrophages which secrete MIP-1 and MCP-1 and these attract lymphocytes into the BMU (Purdue et al. 2006). Revell and Jellie (1998) found IL-15 transcription in macrophages retrieved from interface membrane suggesting specific stimulation of attracted $\mathrm{T}$ cells. The in vitro experiments have revealed active interaction between osteoblasts and $\mathrm{T}$ cells mediated by adhesion scavenger molecule CD6 and integrin LFA-1 (CD11a/CD18) on the side of $\mathrm{T}$ cells with their ligands ALCAM (CD166) and ICAM-1 detected on osteoblast surfaces (Stanley et al. 2006). During this interaction, T cells augment IL-6 expression in osteoblasts resulting in the above-described down-regulation of osteoclasto-genesis. On the other hand, $\mathrm{T}$ cells can influence BMU by expressing RANKL and TRAIL, which stimulate osteoclast maturation (Lee and Lorenzo 2006). RANKL expression on the surface of $T$ cells is up-regulated by TNF- $\alpha$ and IL-1. However, other studies deny any role for T cells in OL ( $\mathrm{Li}$ et al. 2001, Taki et al. 2005) demonstrating OL in lymphocyte-deficient mice. Although the RANKL/RANK/OPG pathway is a clear molecular link between the immune system and particle disease, the role for the clonal immune system in OL development remains to be elucidated.

\section{Possible sources of individual susceptibility to OL}

Although this may appear like looking for the proverbial needle in the haystack, detailed knowledge of OL pathophysiology may facilitate a more effective choice of treatment and preventive targets. In this context, the large individual variation in outcome for the same prostheses under comparable conditions (e.g. similar wear rates) strongly suggests a genetic component to OL. Thus, a search for the "candidate" genetic markers (polymorphisms) has already been initiated. Theoretically, any part of any pathway involved in OL may be affected by nucleotide variation in individual genomes. Wilkinson et al. (2003) have conducted a large study in which the carriers of the TNF- $\alpha-238^{*} \mathrm{~A}$ allele had increased incidence of periprosthetic OL compared to non-carriers $(\mathrm{OR}=1.7)$. Moreover, they found that this variable was an independent risk factor for OL. Recently, a relationship between homozygous genotype $\mathrm{T} / \mathrm{T}$ for $\mathrm{RANK}+575$ and aseptic failure of THA (OR=1.77) was found (Malik et al. 2006). In our pilot collaborative study we reported an association of particular variants of IL- $1 \alpha$ and IL-6 genes with susceptibility to or protection against OL (Ambruzová et $a l$. 2006). Despite these promising results, we should keep in mind the complexity of OL pathophysiology and the hierarchical nature of numerous pathways, predispositions and conditions. 


\section{Therapeutic implications for the future}

Understanding the cascade of events that follow polyethylene wear exposure of periprosthetic tissue may lead to the development of new preventive and treatment approaches. The potential of bisphosphonates, RANKL antagonists, and anti-inflammatory agents are in focus at present (Childs et al. 2001, Shanbhag 2006, von Knoch et al. 2005, Yang et al. 2004). Unfortunately, there is not enough evidence that such approaches work when applied to patients with existing periprosthetic OL. Moreover, there are concerns about the systemic administration of some drugs and some kinds of gene therapy. As a result, there is not approved pharmacological treatment of periprosthetic OL so far.

\section{Conclusions}

The main problem in total hip or knee arthroplasties is polyethylene wear resulting in development of OL. Prosthetic wear debris influences periprosthetic environment complexly and there is strong evidence that monocytes/macrophages are central in these processes. Stimulated macrophages trigger a large number of pathways leading ultimately to uncoupling of the osteoblast/osteoclast balance, and OL. Individual host response may explain why comparable bone defects are not observed in individuals with similar prosthetic wear rate. Preventative measures such as preoperative identification of patients at high risk of early OL development (individual susceptibility) may be possible in the future. It could be based on identification of relevant functional alleles for above mentioned cytokines, adhesion molecules, prostanoids, or any proteins involved in osteoclasts maturation and activation pathways associated with increased OL risk.

\section{Abbreviations}

Akt - serine/threonine protein kinase; AP-1 - activator protein-1 (complex of transcription factors cJun, cFos); BCL-6 - antiapoptotic protein (transcriptional repressor);
BMU - bone multicellular unit; CATK - cathepsin K which degrades collagen type I at several sites in the triple helical region; c-Jun NK - c-Jun N-terminal kinase; COX1 - cyclooxygenase 1 ; c-Src - cellular unmutated form of Rous sarcoma virus oncogen - tyrosine kinase; ERK extracellular signal-regulated kinase; FOXO4 (AFX) ALL1-fused gene from chromosome X (member of "O" subfamily of Forkhead box transcription factors Fox); IF$\kappa \mathrm{B}-$ inhibitor of NF- $\kappa \mathrm{B}$; IF- $\kappa \mathrm{BK}-\mathrm{IF}-\kappa \mathrm{B}$ kinase; IL-1R IL-1 receptor; IL-1 $\alpha$, IL-1 $\beta$, IL-6, IL-4, IL-11 interleukins; JAK - Janus tyrosine kinase associated with cytokine receptor; mi/Mitf - transcriptional regulator microophtalmia transcription factor; NFATc1 - nuclear factor of activated T cells (NFAT) c1 (transcription factor); $\mathrm{NF}-\kappa \mathrm{B}$ - nuclear factor kappa B (complex of transcription factors p50, RelA, p52, RelB or p50, p65); OPG osteoprotegerin, protein - inhibits osteoclastogenesis; p38 protein kinase; $\mathrm{PE}$ - polyethylen; $\mathrm{PGE}_{2}$ - prostaglandin $\mathrm{E}_{2}$; $\mathrm{PI}(3) \mathrm{K}$ - phosphatidylinositol 3-OH kinase; $\mathrm{PKB}$ - protein kinase $\mathrm{B}$; RANK - receptor activator of nuclear factor- $\mathrm{kB}$; RANK-L - ligand for RANK, osteoclast differentiation factor (TRANCE, TN-FSF11); SCF - stem cells factor; STAT - signal transducer and activator of transcription transcription factors family; TNFR - TNF receptor; TNF- $\alpha$ - tumor necrosis factor; TRAF - TNFR-associated cytoplasmic factor; TRAP - tartarate-resistant acid phosphatase; Wnt/ $\beta$-Catenin pathway: low-density lipoprotein receptor-related protein (LRP), frizzled signaling induces preosteoblast replication, osteoblastogenesis, inhibits osteoblast or osteocyte apoptosis.

\section{Conflict of Interest}

There is no conflict of interest.

\section{Acknowledgements}

We wish to thank Dr. A. Oulton for critical reading of this manuscript. Financial support of IGA MH CR grant NR/9490 and grant of Ministry of Education, Youth and Sports of the Czech Republic MSM6198959223.

\section{References}

AMBRUZOVÁ Z, GALLO J, MRÁZEK F, KUBIŠTOVÁ Z, ONDERKOVÁ J, PETŘEK M: Association of cytokine gene polymorphisms with the expansive periprosthetic osteolysis in total hip arthroplasty. Tissue Antigens 67 : $178,2006$.

BLAIR HC, ROBINSON LJ, ZAIDI M: Osteoclast signalling pathways. Biochem Biophys Res Commun 328: 728-738, 2005. 
BOYCE BF, LI P, YAO Z, ZHANG Q, BADELL IR, SCHWARZ EM, O'KEEFE RJ, XING L: TNF-alpha and pathologic bone resorption. Keio J Med 54: 127-131, 2005.

BOYCE BF, SCHWARZ EM, XING L: Osteoclast precursors: cytokine-stimulated immunomodulators of inflammatory bone disease. Curr Opin Rheumatol 18: 427-432, 2006.

BOYLE WJ, SIMONET WS, LACEY DL: Osteoclast differentiation and activation. Nature 423: 337-342, 2003.

CHILDS LM, GOATER JJ, O'KEEFE RJ, SCHWARZ EM: Efficacy of etanercept for wear debris-induced osteolysis. J Bone Miner Res 16: 338-347, 2001.

FRITZ EA, GLANT TT, VERMES C, JACOBS JJ, ROEBUCK KA: Chemokine gene activation in human bone marrow-derived osteoblasts following exposure to particulate wear debris. J Biomed Mater Res A 77: 192-201, 2006.

GALLO J, HAVRÁNEK V, ZAPLETALOVÁ J, ČECHOVÁ I: Influence of demographic, surgical and implant variables on wear rate and osteolysis in ABG I hip arthoplasty. Biomed Pap Med Fac Univ Palacky Olomouc Czech Repub 150: 135-141, 2006.

GARRIGUES GE, CHO DR, RUBASH HE, GOLDRING SR, HERNDON JH, SHANBHAG AS: Gene expression clustering using self-organizing maps: analysis of the macrophage response to particulate biomaterials. Biomaterials 26: 2933-2945, 2005.

GUENTHER R, MORAWIETZ L, FRIEDERICH M, GEHRKE T, FROMMELT L, SCHRODER JH, KRENN V: Expression of CD9, CD11b, CD18, CD52 and PDGFR-beta in the interface membrane of loose endoprostheses. Pathol Res Pract 201: 435-442, 2005.

HARRIS WH: Osteolysis and particle disease in hip replacement. A review. Acta Orthop Scand 65: 113-123, 1994.

HOLDING CA, FINDLAY DM, STAMENKOV R, NEALE SD, LUCAS H, DHARMAPATNI AS, CALLARY SA, SHRESTHA KR, ATKINS GJ, HOWIE DW, HAYNES DR: The correlation of RANK, RANKL and TNFalpha expression with bone loss volume and polyethylene wear debris around hip implants. Biomaterials 27: 5212-5219, 2006.

KONTTINEN YT, XU JW, WARIS E, LI TF, GOMEZ-BARRENA E, NORDSLETTEN L, SANTAVIRTA S: Interleukin-6 in aseptic loosening of total hip replacement prostheses. Clin Exp Rheumatol 20: 485-490, 2002.

KORENY T, TUNYOGI-CSAPO M, GAL I, VERMES C, JACOBS JJ, GLANT TT: The role of fibroblasts and fibroblast-derived factors in periprosthetic osteolysis. Arthritis Rheum 54: 3221-3232, 2006.

KRISHNAN V, BRYANT HU, MACDOUGALD OA: Regulation of bone mass by Wnt signaling. J Clin Invest 116: 1202-1209, 2006.

LEE SK, LORENZO J: Cytokines regulating osteoclast formation and function. Curr Opin Rheumatol 18: 411-418, 2006.

LI TF, SANTAVIRTA S, WARIS V, LASSUS J, LINDROOS L, XU JW, VIRTANEN I, KONTTINEN YT: No lymphokines in T-cells around loosened hip prostheses. Acta Orthop Scand 72: 241-247, 2001.

MA G, AINOLA M, LILJESTROM M, SANTAVIRTA S, PODUVAL P, ZHAO D, CHEN T, KONTTINEN YT: Increased expression and processing of ADAM 12 (meltrin-alpha) in osteolysis associated with aseptic loosening of total hip replacement implants. J Rheumatol 32: 1943-1950, 2005.

MALIK MH, BAYAT A, JURY F, OLLIER WE, KAY PR: Genetic susceptibility to hip arthroplasty failureassociation with the RANK/OPG pathway. Int Orthop 30: 177-181, 2006.

MANDELIN J, LI TF, LILJESTROM M, KROON ME, HANEMAAIJER R, SANTAVIRTA S, KONTTINEN YT: Imbalance of RANKL/RANK/OPG system in interface tissue in loosening of total hip replacement. $J$ Bone Joint Surg Br 85: 1196-1201, 2003.

MANDELIN J, LI TF, HUKKANEN M, LILJESTROM M, SALO J, SANTAVIRTA S, KONTTINEN YT: Interface tissue fibroblasts from loose total hip replacement prosthesis produce receptor activator of nuclear factorkappaB ligand, osteoprotegerin, and cathepsin K. J Rheumatol 32: 713-720, 2005.

MARTIN TJ, SIMS NA: Osteoclast-derived activity in the coupling of bone formation to resorption. Trends Mol Med 11: 76-81, 2005.

MCKELLOP HA, CAMPBELL P, PARK SH, SCHMALZRIED TP, GRIGORIS P, AMSTUTZ HC, SARMIENTO A: The origin of submicron polyethylene wear debris in total hip arthroplasty. Clin Orthop Relat Res 311: 3-20, 1995. 
NALEPKA JL, LEE MJ, KRAAY MJ, MARCUS RE, GOLDBERG VM, CHEN X, GREENFIELD EM: Lipopolysaccharide found in aseptic loosening of patients with inflammatory arthritis. Clin Orthop Relat Res 451: 229-235, 2006.

PARFITT AM: Targeted and nontargeted bone remodeling: relationship to basic multicellular unit origination and progression. Bone 30: 5-7, 2002.

POKORNÝ D, ŠLOUF M, HORÁK Z, JAHODA D, ENTLICHER G, EKLOVÁ S, SOSNA A: Method for assessment of distribution of UHMWPE wear particles in periprosthetic tissues in total hip arthroplasty. Acta Chir Orthop Traumatol Cech 73: 243-250, 2006.

PURDUE PE, KOULOUVARIS P, POTTER HG, NESTOR BJ, SCULCO TP: The cellular and molecular biology of periprosthetic osteolysis. Clin Orthop Relat Res, in press, 2006.

RAKSHIT DS, LY K, SENGUPTA TK, NESTOR BJ, SCULCO TP, IVASHKIV LB, PURDUE PE: Wear debris inhibition of anti-osteoclastogenic signaling by interleukin-6 and interferon-gamma. Mechanistic insights and implications for periprosthetic osteolysis. J Bone Joint Surg Am 88: 788-799, 2006.

REVELL PA, JELLIE SE: Interleukin 15 production by macrophages in the implant interface membrane of aseptically loosened joint replacements. J Mater Sci Mater Med 9: 727-730, 1998.

SHANBHAG AS: Use of bisphosphonates to improve the durability of total joint replacements. J Am Acad Orthop Surg 14: 215-225, 2006.

SIMS N, BARON R: Bone: structure, function, growth, and remodeling. In: Orthopaedics. RH FITZGERALD Jr, H KAUFER, AL MALKANI (eds), Mosby, St. Louis, 2002, pp 147-159.

STAINS JP, CIVITELLI R: Cell-to-cell interactions in bone. Biochem Biophys Res Commun 328: 721-727, 2005.

STANLEY KT, VANDORT C, MOTYL C, ENDRES J, FOX DA: Immunocompetent properties of human osteoblasts: interactions with T lymphocytes. J Bone Miner Res 21: 29-36, 2006.

SUNDFELDT M, CARLSSON LV, JOHANSSON CB, THOMSEN P, GRETZER C: Aseptic loosening, not only a question of wear: a review of different theories. Acta Orthop 77: 177-197, 2006.

TAKI N, TATRO JM, NALEPKA JL, TOGAWA D, GOLDBERG VM, RIMNAC CM, GREENFIELD EM: Polyethylene and titanium particles induce osteolysis by similar, lymphocyte-independent, mechanisms. J Orthop Res 23: 376-383, 2005.

TANAKA Y, NAKAYAMADA S, OKADA Y: Osteoblasts and osteoclasts in bone remodeling and inflammation. Curr Drug Targets Inflamm Allergy 4: 325-328, 2005.

VEIGL D, NIEDERLOVÁ J, KRYŠTŮFKOVÁ O: Periprosthetic osteolysis and its association with the molecule RANKL expression. Physiol Res 56: 455-462, 2007.

VON KNOCH F, HECKELEI A, WEDEMEYER C, SAXLER G, HILKEN G, BRANKAMP J, STERNER T, LANDGRAEBER S, HENSCHKE F, LOER F, VON KNOCH M: Suppression of polyethylene particleinduced osteolysis by exogenous osteoprotegerin. J Biomed Mater Res A 75: 288-294, 2005.

WILKINSON JM, WILSON AG, STOCKLEY I, SCOTT IR, MACDONALD DA, HAMER AJ, DUFF GW, EASTELL R: Variation in the TNF gene promoter and risk of osteolysis after total hip arthroplasty. $J$ Bone Miner Res 18: 1995-2001, 2003.

WILKINSON JM, HAMER AJ, STOCKLEY I, EASTELL R: Polyethylene wear rate and osteolysis: critical threshold versus continuous dose-response relationship. J Orthop Res 23: 520-525, 2005.

WILLERT HG, BUCHHORN GH, FAYYAZI A, FLURY R, WINDLER M, KOSTER G, LOHMANN CH: Metal-onmetal bearings and hypersensitivity in patients with artificial hip joints. A clinical and histomorphological study. J Bone Joint Surg Am 87: 28-36, 2005.

XING L, BOYCE BF: Regulation of apoptosis in osteoclasts and osteoblastic cells. Biochem Biophys Res Commun 328: 709-720, 2005.

YANG SY, WU B, MAYTON L, MUKHERJEE P, ROBBINS PD, EVANS CH, WOOLEY PH: Protective effects of IL-1Ra or vIL-10 gene transfer on a murine model of wear debris-induced osteolysis. Gene Ther 11: 483-491, 2004.

YEUNG RSM: Bones, blood vessels, and the immune system: what's the link? J Rheumatol 32: 2072-2074, 2005. 
ZHANG Q, BADELL IR, SCHWARZ EM, BOULUKOS KE, YAO Z, BOYCE BF, XING L: Tumor necrosis factor prevents alendronate-induced osteoclast apoptosis in vivo by stimulating Bcl-xL expression through Ets-2. Arthritis Rheum 52: 2708-2718, 2005. 